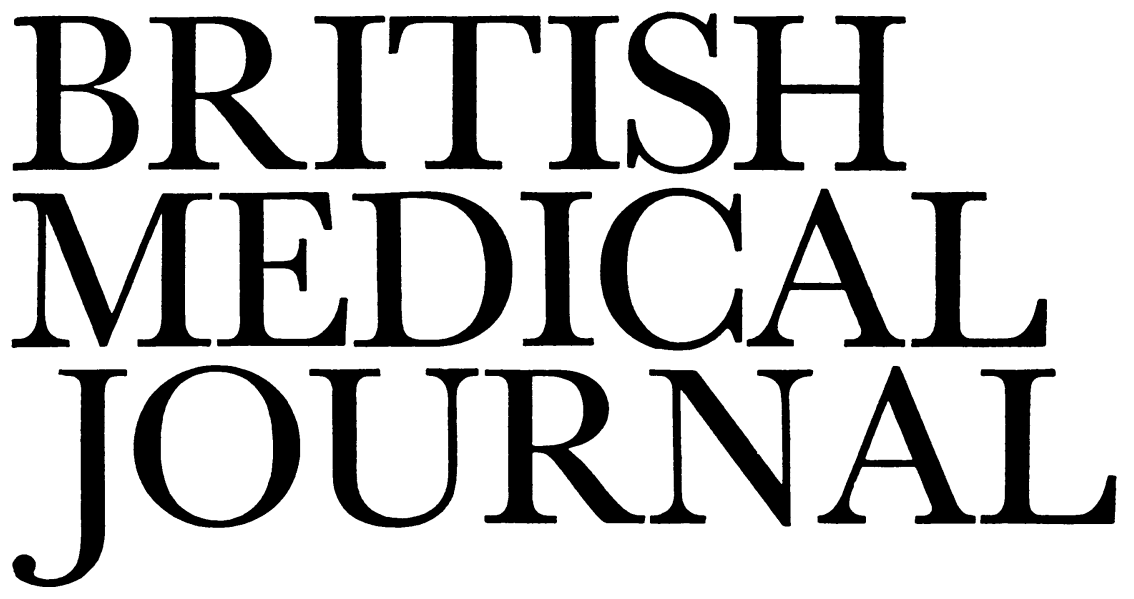

LONDON, SATURDAY 2 MAY 1981

\title{
Mitral valve prolapse
}

Not so long ago a mitral systolic murmur was interpreted by most physicians as mitral reflux occurring through valve cusps deformed by rheumatic endocarditis. That aetiology was the more acceptable if the patient gave a history of acute rheumatism or if a mitral diastolic murmur were also present. In the past 20 years phonocardiography, angiocardiography, and echocardiography, together with pathological studies, have demolished this simple concept; "an information explosion" has occurred, ${ }^{1}$ and phenomena that have been with us for years have acquired new names and a new meaning.

The scarred, shrunken rheumatic valve is now the cause of ever fewer cases of mitral incompetence, and in hospital practice ischaemic heart disease is probably now the most common cause of a mitral systolic murmur, ${ }^{2}$ the reflux here arising from damage to the papillary muscles or to the adjacent left ventricular wall. The term papillary muscle dysfunction ${ }^{3}$ is well established; it implies that the muscular component of the complex mitral apparatus is primarily at fault. A third large group of individuals (with some overlapping) have neither rheumatic heart disease nor coronary disease but nevertheless have abnormal mitral valves. The classic auscultatory signs are a midsystolic click (or clicks) often followed by a midsystolic or late-systolic murmur, and the timing of both characteristically varies with any manoeuvre that alters left ventricular end-diastolic volume. The click is caused by tension of the mitral cusps or chordae and is termed a non-ejection click to distinguish it from the early-systolic click arising from aorta or pulmonary artery or their valves. For this group the generic term mitral valve prolapse is recommended. ${ }^{4}$ Many patients have no other physical signs; they are said to have primary or idiopathic mitral valve prolapse. Others have recognised pathological conditions (such as coronary disease, rheumatic heart disease, atrial septal defect, cardiomyopathy, Marfan's syndrome), and here the dilemma is whether the mitral prolapse is a related abnormality or a coincidence. The cause of the murmur was shown in 1966 to be mitral reflux arising from prolapse of the leaflets, ${ }^{5}$ and the click was found to coincide with the maximal protrusion atrially of the valve leaflet or scallop. The radiological hallmark of the condition is now widely recognised, prolapse of the posterior leaflet beyond the line of the atrioventricular ring being shown in the right anterior oblique projection and that of the anterior leaflet in the left anterior oblique projection. ${ }^{6} 7$ The echocardiogram likewise shows abnormal systolic movement of the cusps (more frequently the posterior) away from the transducer and beyond the point of their initial coaption.

Such ballooning or billowing or prolapse of the leaflets is caused by redundant cusp tissue, giving rise to the term "floppy valve." 8 The prolapse can be shown at necropsy by injecting fluid under pressure into the left ventricle and viewing the valve from the atrium. ${ }^{910}$ Histological examination of the cusps shows an abnormality of collagen in the central layers. 9 In a recent comparison of 50 floppy valves with normal ones Olsen and Al-Rufaie ${ }^{11}$ found a widening of the mucinous layer (zona spongiosa) in nearly all the affected valves. This, they suggest, is the structural anomaly which permits stretching, especially when any other structure controlling mitral function is abnormal. Two-fifths of the patients with floppy valves were found to have ruptured chordae tendineae.

Most patients with mitral prolapse have no symptoms. Some complain of chest pain, palpitation, or dyspnoea; some have abnormal electrocardiograms, ${ }^{12}$ and some arrhythmias; occasionally cerebral emboli occur ${ }^{13}$ and sometimes bacterial endocarditis ${ }^{14}$; some patients eventually require valve replacement for progressive mitral incompetence. Abnormalities of myocardial contraction have been shown ${ }^{15-17}$ and abnormalities found in myocardial biopsy specimens. ${ }^{1819} \mathrm{~A}$ disturbance of myocardial function may, therefore, coincide with the abnormal valve, and debate continues whether the fault is primarily one of the myocardium or of the valve. The condition is undoubtedly common, occurring at all ages and affecting women a little more commonly than men; the line between normal and pathological is hard to draw. An incidence as high as $17 \%$ was found among 100 young women volunteers, ${ }^{20}$ and 6-7\% among young women in the Air Force and also among healthy young men. ${ }^{21}{ }^{22}$ Jeresaty, who has a personal series of 350 patients, estimated the incidence of idiopathic prolapse in the population at about $4 \% \cdot{ }^{23}$ The prognosis during childhood and adolescence is excellent, ${ }^{24}$ as it also is in adults with click or murmur as the only finding. ${ }^{14} 25$

Analysis of the condition has so far failed to produce any tidy synthesis. Reports are legion, terminology is not uniform, and categories are ill-defined or overlap. Dogmatic statements 
on the incidence, aetiology, and prognosis of the condition are still premature. As regards management, most authorities now recommend prophylactic antibiotic cover against bacterial endocarditis when there is a murmur, but not when a click is the only sign $^{23}$; anticoagulant treatment is not justified unless there has been evidence of systemic emboli. Above all the physician must steer the difficult course between engendering anxiety by overconcern and investigation and treating unsympathetically symptoms such as atypical chest pain, which may seem neurotic but which are likely to have a physical basis.

1 Devereux RB, Perloff JK, Reichek N, Josephson ME. Mitral valve prolapse. Circulation $1976 ; 54: 3-14$.

2 Heikkilä J. Mitral incompetence as a complication of acute myocardial infarction. Acta Med Scand 1967 ;suppl 475.

${ }^{3}$ Burch GE, DePasquale NP, Phillips JH. The syndrome of papillary muscle dysfunction. Am Heart f 1968;75:399-415.

4 Abrams J. Mitral valve prolapse: a plea for unanimity. Am Heart $\mathcal{f}$ 1976;92:413-5.

5 Criley JM, Lewis KB, Humphries JO'N, Ross RS. Prolapse of the mitral valve: clinical and cine-angiocardiographic findings. $B r$ Heart $\mathcal{F} 1966$; 28:488-96.

${ }^{6}$ Ranganathan N, Silver MD, Robinson TI, Wilson JK. Idiopathic prolapsed mitral leaflet syndrome. Angiographic-clinical correlations. Circulation 1976;54:707-16.

${ }^{7}$ Cohen MV, Shah PK, Spindola-Franco H. Angiographic-echocardiographic correlation in mitral valve prolapse. Am Heart $\mathcal{F} 1979$;97:43-52.

${ }^{8}$ Read RC, Thal AP, Wendt VE. Symptomatic valvular myxomatous transformation (the floppy valve syndrome). A possible forme fruste of the Marfan syndrome. Circulation 1965;32:897-910.

${ }^{9}$ Davies MJ, Moore BP, Braimbridge MV. The floppy mitral valve. Study of incidence, pathology and complications in surgical, necropsy and forensic material. $\mathrm{Br}$ Heart $\mathcal{F}$ 1978;40:468-81.

10 Becker AE, De Wit APM. Mitral valve apparatus. A spectrum of normality relevant to mitral valve prolapse. Br Heart $\mathcal{f} 1979 ; 42: 680-9$.

11 Olsen EGJ, Al-Rufaie HK. The floppy mitral valve. Study on pathogenesis. Br Heart F 1980;44:674-83.

12 Lardani H, Moreyra A, Manubens S, Belardi J, Fava M, Sheldon WC. Electrocardiographic findings in 125 patients with idiopathic prolapse of the mitral valve studied by angiography. Cleve Clin $Q$ 1976;43: 181-94.

13 Barnett HJM, Jones MW, Boughner DR, Kostuk WJ. Cerebral ischaemic events associated with prolapsing mitral valve. Arch Neurol 1976;33: 777-82.

14 Allen H, Harris A, Leatham A. Significance and prognosis of an isolated late systolic murmur: a 9- to 22 -year follow-up. Br Heart $\mathcal{F} 1974 ; 36$ : 525-32.

${ }^{16}$ Scampardonis G, Yang SS, Maranhäo V, Goldberg H, Gooch AS. Left ventricular abnormalities in prolapsed mitral leaflet syndrome. Review of eighty-seven cases. Circulation 1973;48:287-97.

${ }^{16}$ Liedtke AJ, Gault JH, Leaman DM, Blumenthal MS. Geometry of left ventricular contraction in the systolic click syndrome. Characterization of a segmental myocardial abnormality. Circulation $1973 ; 47: 27-35$.

17 Cobbs BW, King SB. Ventricular buckling: a factor in the abnormal ventriculogram and peculiar hemodynamics associated with mitral valve prolapse. Am Heart $\mathcal{f} 1977 ; 93: 741-58$.

${ }_{18}$ Mason JW, Koch FH, Billingham ME, Winkle RA. Cardiac biopsy evidence for a cardiomyopathy associated with symptomatic mitral valve prolapse. Am $\mathcal{F}$ Cardiol 1978;42:557-62.

19 Malcolm AD, C̄anković-Darracott S, Chayen J, Jenkins BS, WebbPeploe MM. Biopsy evidence of left ventricular myocardial abnormality in patients with mitral-leaflet prolapse and chest pain. Lancet 1979; : 1052-5.

${ }^{20}$ Markiewicz W, Stoner J, London E, Hunt SA, Popp RL. Mitral valve prolapse in one hundred presumably healthy young females. Circulation $1976 ; 53: 464-73$.

${ }^{21}$ Procacci PM, Savran SV, Schreiter SL, Bryson AL. Prevalence of clinical mitral-valve prolapse in 1169 young women. $N$ Engl f Med 1976;294: 1086-8.

${ }^{22}$ Darsee JR, Mikolich JR, Nicoloff NB, Lesser LE. Prevalence of mitral valve prolapse in presumably healthy young men. Circulation $1979 ; 59$ : 619-22.

${ }^{23}$ Jeresaty RM. Mitral valve prolapse. New York: Raven Press, 1979.

${ }^{24}$ Bisset GS, Schwartz DC, Meyer RA, James FW, Kaplan S. Clinical spectrum and long-term follow-up of isolated mitral valve prolapse in 119 children. Circulation 1980;62:423-9.

${ }^{25}$ Barlow JB, Pocock WA. Mitral valve prolapse, the specific billowing mitral leaflet syndrome, or an insignificant non-ejection systolic click. Am Heart $\mathcal{f}$ 1979;97:277-85.

\section{Understanding hepatic regeneration}

The liver has a considerable capacity to regenerate after a surgical or toxic insult. Studies in rats have shown rapid cell division in the first four days after a two-thirds partial hepatectomy, with the size of the liver restored within two to three weeks. ${ }^{1}$ The rate of liver regeneration in man is slower: serial liver scans, liver biopsy specimens, and repeat laparotomy have shown that though regeneration begins within three days of surgical resection, the process is not complete for about six months. ${ }^{2}$

When resection of an otherwise healthy liver is needed to control bleeding after trauma or to remove a localised tumour the mortality is low (once past the immediate postoperative period), with a complete return to normal function. In contrast, when liver resection has been attempted in patients with cirrhosis there is little regeneration; such patients often go into liver failure, leading to coma and death. The clinical circumstances in which liver regeneration is most obviously essential to survival is in fulminant hepatic failure, where there is massive necrosis of liver cells. Liver regeneration may be inhibited in some of these patients because of circulating toxins $^{3}$ or an unfavourable hormonal balance, but the explanation is far from well defined.

Indeed, despite much research into the factors that control regeneration of the liver many of the mysteries remain. A distinction needs to be drawn between those substances that initiate cell division and those that promote regeneration once it has begun. Most hypotheses have centred on blood-borne factors that might control regeneration. There may be stimulatory substances which are normally removed by the intact liver or else hepatotrophic substances which are released by the damaged liver or another organ in response to liver damage. Alternatively, the liver may continuously produce inhibitory substances, whose concentrations fall with liver damage. ${ }^{45}$

For some time the altered blood flow within the hepatic remnant was considered to be the main stimulus for regrowth, but careful studies in animals showed that regeneration still occurred after portal ligation or portacaval shunt. Hormones - particularly those from the gut-are now thought likely to play an important part in liver regeneration. ${ }^{6}$ Infusion of both insulin and glucagon into eviscerated rats promotes regeneration of the liver and will increase survival rates in mice with liver failure due to murine hepatitis virus. Thyroxine, parathyroid hormone, calcitonin, growth hormone, and epidermal growth factor (an insulin-like peptide chemically identical with urogastrone) will increase liver regeneration, whereas adrenal hormones suppress the response.

Some recent studies, particularly those of Terblanche $e t a l^{7}$ and Goldberg et $a l,{ }^{8}$ have focused attention on a hepatic regenerative stimulator substance which can be extracted from the regenerating liver. This factor has been prepared from both dogs and rats after partial hepatectomy and will stimulate synthesis of DNA and mitosis in both normal animals and those that have had a partial hepatectomy. Further work is needed to characterise this substance. The part possibly played by prostaglandins in the early stages of liver regeneration is now being investigated. Increased concentrations of prostaglandin $E_{1}$ have been found in portal blood. Inhibitors of prostaglandin synthesis inhibit synthesis of DNA in the hepatic remnant ${ }^{9}$ and their contribution should be evaluated further. 